\title{
Motivation and emotion and the society for the study of motivation: A joint venture
}

\author{
Richard M. Ryan
}

Published online: 17 March 2010

(C) Springer Science+Business Media, LLC 2010

Motivation and Emotion is pleased to become the official journal of the recently formed Society for the Study of Motivation (SSM). We are especially pleased to support SSM, the emergence of which reflects the resurgent vitality of the field of motivation as it reclaims its place at the center stage of behavioral sciences.

As regular readers of Motivation and Emotion know, this journal too is resurgent, mirroring our changing field. In the past 4 years, with the support of its publishers at Springer and a new editorial team, Motivation and Emotion has well more than doubled in yearly submissions and nearly doubled in the number of publications. That is, we are more selective, yet printing more contributions. We also virtually doubled in page size, providing more content per article, and over this short period, our impact ratings have doubled as well. While such numbers are interesting, we are not focused on the numbers but on a mission: To provide a high-quality venue for new empirical research and ideas in this field.

Our new association with SSM reflects our desire at $M$ $\& E$ to become even more representative of the field of motivation and emotion as a whole. Two upcoming special issues, for example, exemplify some of the most active areas of current research. Already in process is a special issue on implicit and explicit processes in motivation and emotion edited by Hugo Kehr, Rex Wright, and Todd Thrash. And soon to be announced (look in our June issue!) will be a call for papers for a special issue on neuroscience perspectives on motivation and emotion, edited by Jack van Honk, Eddie Harmon-Jones and Johnmarshall Reeve. We look for some exciting contributions in both of these special issues, and to continuing to print the latest developments in our regular issues.

It is our hope that the association between Motivation and Emotion and the Society for the Study of Motivation will constitute a synergistic effort that supports rigorous empirical scholarship in motivational and affective processes that cuts across biological, psychological, and cultural perspectives and methods of inquiry. It is a joint venture to build more great science in an area of utmost importance to our disciplines, and to our world.
R. M. Ryan ( $\square)$

University of Rochester, Rochester, NY, USA

e-mail: ryan@psych.rochester.edu 